\title{
Editorial: New Insights into Estrogen/Estrogen Receptor Effects in the Cardiac and Skeletal Muscle
}

\author{
Dawn A. Lowe ${ }^{1}$ and Georgios Kararigas ${ }^{2,3 *}$ \\ 'Department of Rehabilitation Medicine, University of Minnesota, Minneapolis, MN, United States, ${ }^{2}$ Charité - \\ Universitätsmedizin Berlin, Corporate Member of Freie Universität Berlin, Humboldt-Universität zu Berlin, and Berlin Institute \\ of Health, Berlin, Germany, ${ }^{3}$ DZHK (German Centre for Cardiovascular Research), Partner Site Berlin, Berlin, Germany
}

Keywords: cardiovascular disease, estrogen, heart, receptor, skeletal muscle, steroid

\section{Editorial on the Research Topic}

\section{New Insights into Estrogen/Estrogen Receptor Effects in the Cardiac and Skeletal Muscle}

Decreased levels of the steroid hormone estrogen at menopause are associated with an increased incidence of cardiovascular disease and loss of skeletal muscle mass and strength. Consequently, it has been generally expected that estrogen may be a crucial protective factor against the development of cardiovascular disease and that it may be implicated in the regulation of skeletal muscle function in women. Estrogen signals through the classical nuclear estrogen receptors (ER) $\alpha$ and $\beta$, as well as the membrane G protein-coupled receptor GPR30 (also referred to as GPER), via the genomic

OPEN ACCESS

Edited and reviewed by: Pierre De Meyts,

Université Catholique de Louvain, Belgium

*Correspondence: Georgios Kararigas georgekararigas@gmail.com

Specialty section:

This article was submitted to Molecular and Structural Endocrinology,

a section of the journal Frontiers in Endocrinology

Received: 26 February 2020 Accepted: 02 March 2020 Published: 19 March 2020

Citation: Lowe DA and Kararigas G (2020) Editorial: New Insights into Estrogen/Estrogen Receptor Effects in the Cardiac and Skeletal Muscle.

Front. Endocrinol. 11:141 doi: 10.3389/fendo.2020.00141 or non-genomic pathway.

Studies reporting actions of estrogen in the heart show direct cardiac estrogenic effects $(1,2)$, which may differ significantly between the sexes (3-6). In this Research Topic, Ueda et al. provide an overview of ER signaling in the cardiovascular system, including cardiac myocytes and fibroblasts. Considerable effort has focused on non-nuclear ER signaling and non-genomic effects of estrogen. Accordingly, Puglisi et al. review non-genomic effects of estrogen on cell homeostasis and remodeling focusing on cardiac ischemia/reperfusion injury.

Mitochondrial bioenergetics are at the core of cardiac and skeletal muscle function. Ventura-Clapier et al. provide an overview of the effects of estrogen and its receptors in cardiac and skeletal muscle mitochondria. Mahmoodzadeh and Dworatzek take a closer look and review the regulation of cardiac mitochondrial function and $\mathrm{Ca}^{2+}$ ion channels by $17 \beta$-estradiol (E2) and its receptors, thereby affecting contractile function. The E2/ER axis also impacts skeletal muscle contractility and mitochondrial bioenergetics (7-11). Counts et al. report in their original research study that mitochondrial dysfunction was attenuated by the administration of E2 in a genetic mouse model of cachexia. In addition to regulating mitochondrial bioenergetics, estrogen is expected to confer protection against oxidative stress. In their original research article, Ogola et al. provide insight into how acute estrogen signaling via GPER provides cardiovascular protection in angiotensin II-induced hypertension characterized by increased oxidative stress.

The decline of estrogen at menopause is associated with changes in several cardiovascular risk factors, including the atherogenic lipid profile and calcification in cardiovascular structures. In this context, Zhang et al. provide a review of the effects of estrogen in basic biological pathways associated with vascular and cardiac valvular tissue calcification, as well as potential strategies of pharmacological therapy to reduce or slow these processes. Karvinen et al. investigated whether physical activity attenuates changes in the atherogenic lipid profile and cardiovascular risk in 
postmenopausal women. Their results suggest that physical activity may attenuate menopause-associated atherogenic changes of healthy middle-aged women to a certain extent. Interestingly, physical activity, in turn, is affected by estrogen $(12,13)$.

The E2/ER axis may also affect immune responses, thereby affecting the risk of infection and subsequent development of inflammatory heart disease, such as myocarditis, which may lead to cardiomyopathy and heart failure. In their original research study, Bruno et al. found that exposure to the endocrine disruptor bisphenol A led to altered ER expression in the heart, suggesting an increased risk of developing myocarditis after a viral infection in females.

Pronounced sex differences exist in the development and pathophysiology of cardiovascular diseases (14), such as pressure overload-induced left ventricular hypertrophy (15-20), as well as the response to therapy $(21,22)$. Estrogen is thought to play a major role in cardiovascular sex differences. Notably, it has been put forward that the decrease of estrogen at menopause may be a contributor to the development of heart failure with preserved ejection fraction (23), which mostly affects women (24). Considering the potential underlying pathomechanisms, Sickinghe et al. propose the hypothesis that the menopauserelated estrogen decline contributes to myocardial microvascular dysfunction and they provide an overview of molecular targets of estrogen that might guide future research and treatment options. Along this line, Groban et al. outline the impact of GPER on diastolic function, left ventricular stiffness and aortic distensibility, among others.

\section{REFERENCES}

1. Kararigas G, Nguyen BT, Zelarayan LC, Hassenpflug M, Toischer K, SanchezRuderisch H, et al. Genetic background defines the regulation of postnatal cardiacgrowth by 17beta-estradiol through a beta-catenin mechanism. Endocrinology. (2014) 155:2667-76. doi: 10.1210/en.2013-2180

2. Scheuer J, Malhotra A, Schaible TF, Capasso J. Effects of gonadectomy and hormonal replacement on rat hearts. Circ Res. (1987) 61:12-9. doi: 10.1161/01.RES.61.1.12

3. Kararigas G, Fliegner D, Forler S, Klein O, Schubert C, Gustafsson JA, et al. Comparative proteomic analysis reveals sex and estrogen receptor beta effects in the pressure overloaded heart. J Proteome Res. (2014) 13:5829-36. doi: $10.1021 / \operatorname{pr} 500749 j$

4. Sanchez-Ruderisch H, Queiros AM, Fliegner D, Eschen C, Kararigas G, Regitz-Zagrosek V. Sex-specific regulation of cardiac microRNAs targeting mitochondrial proteins in pressure overload. Biol Sex Differ. (2019) 10:8. doi: 10.1186/s13293-019-0222-1

5. Murphy E, Steenbergen C. Estrogen regulation of protein expression and signaling pathways in the heart. Biol Sex Differ. (2014) 5:6. doi: 10.1186/2042-6410-5-6

6. Hein S, Hassel D, Kararigas G. The Zebrafish (Danio rerio) is a relevant model for studying sex-specific effects of 17 beta-estradiol in the adult heart. Int J Mol Sci. (2019) 20:E6287. doi: 10.3390/ijms20246287

7. Collins BC, Laakkonen EK, Lowe DA. Aging of the musculoskeletal system: How the loss of estrogen impacts muscle strength. Bone. (2019) 123:137-44. doi: 10.1016/j.bone.2019.03.033

8. Moran AL, Nelson SA, Landisch RM, Warren GL, Lowe DA. Estradiol replacement reverses ovariectomy-induced muscle contractile and myosin dysfunction in mature female mice. J Appl Physiol. (2007) 102:1387-93. doi: 10.1152/japplphysiol.01305.2006
Collectively, this Research Topic includes clinical- and preclinical studies in original research and state-of-the-art review articles focusing on the effects of estrogen on cardiovascular physiology and skeletal muscle biology and function. Detailed characterization of the regulation of (patho)physiology by estrogen and its receptors in cardiac and skeletal muscle, along with elucidation of the underlying mechanisms may lead to the identification of novel therapeutic targets, which may have a wide implication in the development of new and personalized therapies.

\section{AUTHOR CONTRIBUTIONS}

GK conceived the work and drafted the manuscript. DL revised critically the manuscript. DL and GK read and approved of the submitted manuscript.

\section{FUNDING}

DL acknowledges support from the National Institutes of Health (R01AG031743 and R01AG062899). GK acknowledges support from the DZHK (German Centre for Cardiovascular Research) and the BMBF (German Ministry for Education and Research).

\section{ACKNOWLEDGMENTS}

We thank the authors of this Research Topic for their contributions and the reviewers for their evaluations.

9. Spangenburg EE, Geiger PC, Leinwand LA, Lowe DA. Regulation of physiological and metabolic function of muscle by female sex steroids. Med Sci Sports Exerc. (2012) 44:1653-62. doi: 10.1249/MSS.0b013e31825 $871 \mathrm{fa}$

10. Schneider BS, Fine JP, Nadolski T, Tiidus PM. The effects of estradiol and progesterone on plantarflexor muscle fatigue in ovariectomized mice. Biol Res Nurs. (2004) 5:265-75. doi: 10.1177/1099800403262258

11. Hevener AL, Ribas V, Moore TM, Zhou Z. The impact of skeletal muscle ERalpha on mitochondrial function and metabolic health. Endocrinology. (2020) 161:bqz017. doi: 10.1210/endocr/bqz017

12. Cabelka CA, Baumann CW, Collins BC, Nash N, Le G, Lindsay A, et al. Effects of ovarian hormones and estrogen receptor alpha on physical activity and skeletal muscle fatigue in female mice. Exp Gerontol. (2019) 115:155-64. doi: 10.1016/j.exger.2018.11.003

13. Andersen RE, Crespo CJ, Franckowiak SC, Walston JD. Leisure-time activity among older U.S. Women in relation to hormone-replacement-therapy initiation. J Aging Phys Activity. (2003) 11:82. doi: 10.1123/japa.11.1.82

14. Kararigas G, Seeland U, Barcena de Arellano ML, Dworatzek E, Regitz-Zagrosek V. Why the study of the effects of biological sex is important. Commentary. Ann Ist Super Sanita. (2016) 52:149-50. doi: 10.4415/ANN_16_02_03

15. Aurigemma GP, Silver KH, McLaughlin M, Mauser J, Gaasch WH. Impact of chamber geometry and gender on left ventricular systolic function in patients > 60 years of age with aortic stenosis. Am J Cardiol. (1994) 74:794-8. doi: 10.1016/0002-9149(94)90437-5

16. Carroll JD, Carroll EP, Feldman T, Ward DM, Lang RM, McGaughey D, et al. Sex-associated differences in left ventricular function in aortic stenosis of the elderly. Circulation. (1992) 86:1099-107. doi: 10.1161/01.CIR.86.4.1099

17. Douglas PS, Otto CM, Mickel MC, Labovitz A, Reid CL, Davis KB. Gender differences in left ventricle geometry and function in patients 
undergoing balloon dilatation of the aortic valve for isolated aortic stenosis. NHLBI Balloon Valvuloplasty Registry. Br Heart J. (1995) 73:548-54. doi: 10.1136/hrt.73.6.548

18. Gaignebet L, Kandula MM, Lehmann D, Knosalla C, Kreil DP, Kararigas G. Sex-specific human cardiomyocyte gene regulation in left ventricular pressure overload. Mayo Clin Proc. (2020). doi: 10.1016/j.mayocp.2019.11.026. [Epub ahead of print].

19. Kararigas G, Dworatzek E, Petrov G, Summer H, Schulze TM, Baczko I, et al. Sex-dependent regulation of fibrosis and inflammation in human left ventricular remodelling under pressure overload. Eur J Heart Fail. (2014) 16:1160-7. doi: 10.1002/ejhf.171

20. Villari B, Campbell SE, Schneider J, Vassalli G, Chiariello M, Hess OM. Sex-dependent differences in left ventricular function and structure in chronic pressure overload. Eur Heart J. (1995) 16:1410-9. doi: 10.1093/oxfordjournals.eurheartj.a060749

21. Gaignebet L, Kararigas G. En route to precision medicine through the integration of biological sex into pharmacogenomics. Clin Sci. (2017) 131:329-42. doi: 10.1042/CS20160379

22. Franconi F, Campesi I. Pharmacogenomics, pharmacokinetics and pharmacodynamics: interaction with biological differences between men and women. Br J Pharmacol. (2014) 171:580-94. doi: 10.1111/bph.12362
23. Sabbatini AR, Kararigas G. Menopause-related estrogen decrease and the pathogenesis of HFpEF: JACC review topic of the week. J Am Coll Cardiol. (2020) 75:1074-82. doi: 10.1016/j.jacc.2019. 12.049

24. Lam CS, Carson PE, Anand IS, Rector TS, Kuskowski M, Komajda M, et al. Sex differences in clinical characteristics and outcomes in elderly patients with heart failure and preserved ejection fraction: the Irbesartan in Heart Failure with Preserved Ejection Fraction (I-PRESERVE) trial. Circ Heart Fail. (2012) 5:571-8. doi: 10.1161/CIRCHEARTFAILURE.112. 970061

Conflict of Interest: The authors declare that the research was conducted in the absence of any commercial or financial relationships that could be construed as a potential conflict of interest.

Copyright (๑) 2020 Lowe and Kararigas. This is an open-access article distributed under the terms of the Creative Commons Attribution License (CC BY). The use, distribution or reproduction in other forums is permitted, provided the original author(s) and the copyright owner(s) are credited and that the original publication in this journal is cited, in accordance with accepted academic practice. No use, distribution or reproduction is permitted which does not comply with these terms. 